\title{
Structure and Antioxidant Activity of Soy Protein Isolate-Dextran Conjugates Obtained by $\mathrm{TiO}_{2}$ Photocatalysis
}

\author{
Bei Jin, ${ }^{1,2,3}$ Xiaosong Zhou, ${ }^{1,3}$ Bing Li, ${ }^{2}$ Caiyan Chen, ${ }^{1}$ Xiaosa Zhang, ${ }^{1}$ and Siqiao Chen ${ }^{1}$ \\ ${ }^{1}$ School of Chemistry and Chemical Engineering and Institute of Food Science \& Engineering, Lingnan Normal University, \\ Zhanjiang 524048, China \\ ${ }^{2}$ Engineering Research Center of Starch and Vegetable Protein Processing, South China University of Technology, \\ Ministry of Education, Guangzhou 510640, China \\ ${ }^{3}$ Development Center for New Materials Engineering and Technology, Lingnan Normal University, Zhanjiang 524048, China
}

Correspondence should be addressed to Bei Jin; jinbeikim2013@163.com

Received 29 January 2015; Accepted 31 March 2015

Academic Editor: Nikos Chorianopoulos

Copyright (c) 2015 Bei Jin et al. This is an open access article distributed under the Creative Commons Attribution License, which permits unrestricted use, distribution, and reproduction in any medium, provided the original work is properly cited.

\begin{abstract}
The aim of this study was to investigate the structural characteristics and antioxidant activities of soy protein isolate- (SPI-) dextran conjugates obtained by $\mathrm{TiO}_{2}$ photocatalysis treatment. Results revealed that the UV-vis absorption and the fluorescence intensity increased as the photocatalytic power increased $(P<0.05)$. Higher photocatalytic power could promote the extent of glycation and the formation of high molecular weight SPI-dextran conjugates, which were evidenced by free amino group content and sodium dodecyl sulphate-polyacrylamide gel electrophoresis (SDS-PAGE) analysis. The Fourier transform infrared (FT-IR) spectra suggested that the amide I, II, and III bands of SPI were altered by the glycation induced by $\mathrm{TiO}_{2}$ photocatalysis. Moreover, significant changes of secondary structure occurred in SPI-dextran conjugates. The $\alpha$-helix, $\beta$-sheet, $\beta$-turns, and random coil were changed from approximately $10.6 \%, 37.9 \%, 12.9 \%$, and $38.6 \%$ to $3.8 \%, 10.4 \%, 17.7 \%$, and $68.8 \%$, respectively, after treatment at photocatalytic power of $1000 \mathrm{~W}$. In addition, SPI-dextran conjugates obtained by $\mathrm{TiO}_{2}$ photocatalysis treatment exhibited high hydroxyl radical scavenging activity and possessed increased reducing power. All data indicated that $\mathrm{TiO}_{2}$ photocatalysis was an efficient method for promoting protein-polysaccharide copolymerisation.
\end{abstract}

\section{Introduction}

Many modified technologies such as alkylation, esterification, amidination, deamidination, covalent attachment of carbohydrates and fatty acids, thiol-disulfide exchange, and enzymatic modification can effectively improve the functional properties of proteins [1]. Maillard-type protein-polysaccharide conjugates, the product of nonenzymatic browning reaction which is one of the major food protein modifying reactions occurring during thermal food processing, can contribute markedly to the aroma, taste, and colour, as well as to antioxidant potential of stored and processed foods [2]. In addition, Maillard products can be added to foods as functional ingredients to improve the emulsion, gelation, appearance, and texture of food products [3]. However, protein-polysaccharide glycation reaction is time consuming and it is difficult to control the reaction process when using classical glycation reactions, such as dry heating method and wet heating method $[1,4]$. Thus, it is necessary to find a novel technology to improve the efficiency of glycation reactions.

Novel physical technologies such as gamma irradiation [5] and pulsed electric field [6] and high intensity ultrasound [7] have been investigated as full or partial alternatives to conventional heat treatment because these technologies can greatly speed up the glycation reaction and improve the functional properties of proteins. There is a growing scientific interest in the influence of photocatalysis on synthesis of compounds with improved properties. Photocatalysis provides a green chemical route for organic functional group transformation under mild conditions. In the past two decades, it has been successfully applied to organic synthesis such as polymerization, hydroxylation of aromatic, oxidation of amine, epoxidation of olefins, and carbonylation [8-12]. In these reactions, no other chemical reagents are introduced 
and there is no need to control temperature, and the reaction time is shortened. However, the effect of $\mathrm{TiO}_{2}$ photocatalysis on the glycation reaction has scarcely been reported. Thus, this study aims to prepare SPI-dextran conjugate induced by $\mathrm{TiO}_{2}$ photocatalysis treatment and evaluate the antioxidant activities and the structural changes of the resulting conjugates.

\section{Materials and Methods}

2.1. Chemicals. Dextran (MW: 60,000-90,000) was purchased from Chanshou Biological Co., Ltd. (Jiashu Province, China). SPI was obtained from Wonderful Tech. Co. (Shandong Province, China), containing (on dry basis) $6.5 \%$ moisture, $1.0 \%$ ash, $0.2 \%$ lipid, and $90.2 \%$ protein (determined by Kjeldahl method, N×6.25). 1, 1-Diphenyl-2picrylhydrazyl (DPPH), o-phthaldialdehyde (OPA), and 8anilino-1-naphthalenesulfonic acid (ANS) were purchased from Sigma Chemical Co. (St. Louis, MO, USA). Acrylamide (99\%) was purchased from Sigma (Deisenhofen, Germany) and HMF (98\%) was from Acros (Geel, Belgium). All other chemicals used were of analytical grade and procured from Merck (Darmstadt, Germany).

2.2. Preparation of SPI-Dextran Conjugates. The photocatalytic conjugation was conducted in a $50 \mathrm{~mL}$ cylindrical glass vessel fixed in a XPA-II photochemical reactor (Nanjing Xujiang Machine-electronic Plant). The filter system comprises a house-made filter mounted on the lamp to eliminate infrared irradiation and a UV filter which can absorb the light with wavelength less than $400 \mathrm{~nm}$. The mixtures of soy protein and dextran in the weight ratio of $1: 1$ were dissolved in $20 \mathrm{mM}$ potassium phosphate buffer ( $\mathrm{pH} 8$ ). Then, the solution was stirred for $3 \mathrm{~h}$ at an ambient temperature until soy protein and dextran completely dissolved. The $\mathrm{pH}$ of the solution was adjusted to 8.0 by adding $0.1 \mathrm{~N} \mathrm{HCl}$ or $0.2 \mathrm{~N} \mathrm{NaOH}$. The SPI-dextran solution was ready for the photocatalytic reaction tests. For each test, $20 \mathrm{~mL}$ soy proteindextran solution was placed in a $50 \mathrm{~mL}$ jacketed vessel with a constant flow of $4 \pm 2^{\circ} \mathrm{C}$ circulation water at a rate of $0.6 \mathrm{~L} / \mathrm{min}$ to maintain a sample temperature below $40^{\circ} \mathrm{C}$. The SPI-dextran solutions were treated at photocatalytic power of 500 (TP1) and $1000 \mathrm{~W}$ (TP2) for $2 \mathrm{~h}$. As a contrast, thermal treated samples were prepared under $40 \pm 2^{\circ} \mathrm{C}$ for $2 \mathrm{~h}$ with the same soy protein-dextran mixture (control samples). All samples were kept at $4^{\circ} \mathrm{C}$ before chemical analysis within $24 \mathrm{~h}$ or freeze-dried and then stored at $-20^{\circ} \mathrm{C}$ for further analysis. Further details of photocatalytic reactor could be found in [13].

2.3. Spectrophotometric Analyses and Spectrofluorimetry Measurements. The UV-absorbance and browning of SPIdextran conjugates were measured according to the method of Rao et al. [5] with a slight modification. The absorbance at 294 was measured in 20-fold diluted samples and $420 \mathrm{~nm}$ was measured in undiluted samples by a UV-2550 spectrophotometer (Shimadzu, Kyoto, Japan) for detecting UVabsorbance and browning intensity, respectively. Fluorescence measurements were performed using F4500 fluorescence-spectrophotometre (Hitachi Co., Japan). The fluorescence of the glycation products was measured at an excitation wavelength of $290 \mathrm{~nm}$ and an emission wavelength $300-450 \mathrm{~nm}$ in protein samples of $0.5 \mu \mathrm{M}$ in $20 \mathrm{mM}$ potassium phosphate buffer ( $\mathrm{pH}$ 7.2).

2.4. Determination of Free Amino Groups Content. The content of free amino groups was determined by the OPA method. The OPA reagent was prepared according to Caillard et al. [14]. OPA ( $80 \mathrm{mg}$ ) was dissolved in $2 \mathrm{~mL} \mathrm{95 \%} \mathrm{ethanol}$ and mixed with $50 \mathrm{~mL} 0.1 \mathrm{M}$ sodium tetraborate buffer solution at $\mathrm{pH} 9.5,5 \mathrm{~mL}$ of $20 \%$ (W/V) SDS, and $0.2 \mathrm{~mL} 2$ mercaptoethanol. The mixtures were then diluted with water to $100 \mathrm{~mL}$ for forming the OPA reagent. The OPA reagent was prepared freshly before use. $1 \mathrm{~mL}$ OPA reagent was added to $50 \mu \mathrm{L}$ of the treated soy protein-dextran conjugates and incubated in the dark at $35^{\circ} \mathrm{C}$ for $2 \mathrm{~min}$, and the absorption at $340 \mathrm{~nm}$ was measured immediately in order to obtain the free amino groups.

2.5. Determination of Hydroxyl Radical Scavenging Activity and Reducing Power. The hydroxyl radical scavenging activity of the SPI-dextran conjugates was determined according to the method of You et al. [15]. A mix of $600 \mu \mathrm{L}$ of $1,10-$ phenanthroline $(5.0 \mathrm{mM}), 600 \mu \mathrm{L}$ of $\mathrm{FeSO}_{4}(5.0 \mathrm{mM})$, and $600 \mu \mathrm{L}$ of ethylenediaminetetraacetic acid (EDTA) $(15 \mathrm{mM})$ was mixed with $400 \mu \mathrm{L}$ of sodium phosphate buffer $(0.2 \mathrm{M}$, $\mathrm{pH}$ 7.4). Then $600 \mu \mathrm{L}$ of samples $(2.0 \mathrm{mg} / \mathrm{mL})$ and $800 \mu \mathrm{L}$ of $\mathrm{H}_{2} \mathrm{O}_{2}(0.01 \%)$ were added. The mixture was incubated at $37^{\circ} \mathrm{C}$ for $60 \mathrm{~min}$, and the absorbance was measured at 536 nm (UV754, Xianjian Scientific Instrument Co., Shanghai, China). Results were determined using the following equation:

$$
\begin{aligned}
& \text { Hydroxyl radical scavenging activity (\%) } \\
& =\left(A_{s}-A_{0}\right) \times \frac{100}{\left(A_{c}-A_{0}\right)},
\end{aligned}
$$

where $A_{s}$ is the absorbance of the sample, $A_{0}$ is the absorbance of the blank solution using distilled water instead of sample, and $A_{c}$ is the absorbance of a control solution in the absence of $\mathrm{H}_{2} \mathrm{O}_{2}$.

The reducing power of conjugation was determined according to the method of Zheng et al. [16] with some modification. Briefly, $2.0 \mathrm{~mL}$ of sample was mixed with $2.0 \mathrm{~mL}$ of $0.2 \mathrm{M}$ sodium phosphate buffer $(\mathrm{pH}=6.6)$ and $2.0 \mathrm{~mL}$ of $1 \%(\mathrm{w} / \mathrm{v})$ potassium ferricyanide. The mixture solution was incubated at $50^{\circ} \mathrm{C}$ for $20 \mathrm{~min}$ followed by the addition of $2.0 \mathrm{~mL}$ of $10 \%$ trichloroacetic acid. The mixtures were centrifuged at $3000 \mathrm{r} / \mathrm{min}$ for $10 \mathrm{~min}$. $2.0 \mathrm{~mL}$ of the supernatant was collected and mixed with $2.0 \mathrm{~mL}$ of distilled water and $0.4 \mathrm{~mL}$ of $0.1 \%(\mathrm{w} / \mathrm{v}) \mathrm{FeCl}_{3}$. After standing at room temperature for $10 \mathrm{~min}$, the absorbance of the reaction mixture was measured spectrophotometrically at $700 \mathrm{~nm}$. An equivalent volume of distilled water instead of the sample was used as the blank. Increased absorbance of the reactions mixture indicated increased reducing power. 
2.6. Electrophoresis. SDS-polyacrylamide gel electrophoresis (SDS-PAGE) was examined by vertical gel electrophoresis equipment (Mini-Protean II; Bio-Rad Laboratories, Richmond, CA) [17]. The sample (10 $\mu \mathrm{g})$ was added with laemmli buffer in the presence of $2 \% \beta$-mercaptoethanol and heated at $100^{\circ} \mathrm{C}$ for $5 \mathrm{~min}$ before loading into gel. The electrophoresis was carried out at a constant current of $15 \mathrm{~mA}$ using $4 \%$ stacking gel and $10 \%$ running gel. After separation, Gels were stained with $0.2 \%$ Coomassie Brilliant Blue R-250 in 25\% methanol and $10 \%$ acetic acid. Destaining was conducted with a solution of $40 \%$ methanol and $10 \%$ acetic acid. Then, the gels were scanned and analyzed.

2.7. Fourier Transform Infrared (FT-IR) Measurement. The infrared analysis was performed using the FT-IR technique according to the method described by Gao et al. [18] with a slight modification. FTIR spectra were measured on a FT-IR spectrometer (NICOLET NEXUS470, DTGS) with a $4 \mathrm{~cm}^{-1}$ resolution and 32 scans between wavenumbers of $4000 \mathrm{~cm}^{-1}$ and $400 \mathrm{~cm}^{-1}$. The freeze-dried samples were prepared as $\mathrm{KBr}$ disks with $1 \mathrm{mg}$ of the samples in $100 \mathrm{mg}$ of $\mathrm{KBr}$. Background noise was corrected with pure $\mathrm{KBr}$ data. The spectra were averaged and smoothed, and their baselines were calibrated with the Spectra Manager software (Jasco Inc., Easton, MD, USA).

2.8. CD Spectra Measurements and CD Spectra Analysis. The secondary structure of proteins was determined by $\mathrm{CD}$ at $25^{\circ} \mathrm{C}$ in the far UV (from 190 to $250 \mathrm{~nm}$ ) using a CD6 Jobin-Yvon dichrograph. Spectra were recorded at a protein concentration of $0.5 \mathrm{mg} / \mathrm{mL}$ in $20 \mathrm{mM}$ PBS (pH 7.2) after the centrifugation at $5,000 \times \mathrm{g}$ to remove any insoluble residue using a $2 \mathrm{~mm}$ path length quartz cuvette. Secondary structure was estimated using the CONTIN software. Four secondary structures: $\alpha$-helix, $\beta$-sheet, $\beta$-turns, and unordered coil, were calculated. Data were the means of triplicate measurements.

2.9. Statistical Analysis. All analyses were done in triplicate, and data are reported as means \pm standard deviation. Differences between the variables were tested for significance by one-way ANOVA accompanied with Tukey's post hoc test using Origin 7.5. A value of $P<0.05$ was considered significant.

\section{Results and Discussion}

3.1. Changes in $A_{294}$, Browning Intensity and Fluorescence Intensity. The changes of $A_{294}$ and browning intensity of SPIdextran model solution with different photocatalytic power levels are shown in Figure 1. Both $A_{294}$ and browning changed significantly $(P<0.05)$ at photocatalytic power of 500 and $1000 \mathrm{~W}$ within $2 \mathrm{~h}$. The $A_{294}$ of SPI-dextran solution increased from approximately 0.28 to 0.84 and 1.06 as photocatalytic power of 500 and $1000 \mathrm{~W}$, respectively; in the case of $A_{420}$, it increased from approximately 0 to 0.21 and 0.36 at photocatalytic power of 500 and $1000 \mathrm{~W}$, respectively. The brown pigment development, indicated by $A_{420}$, coincided with the colourless intermediate formation evidenced by

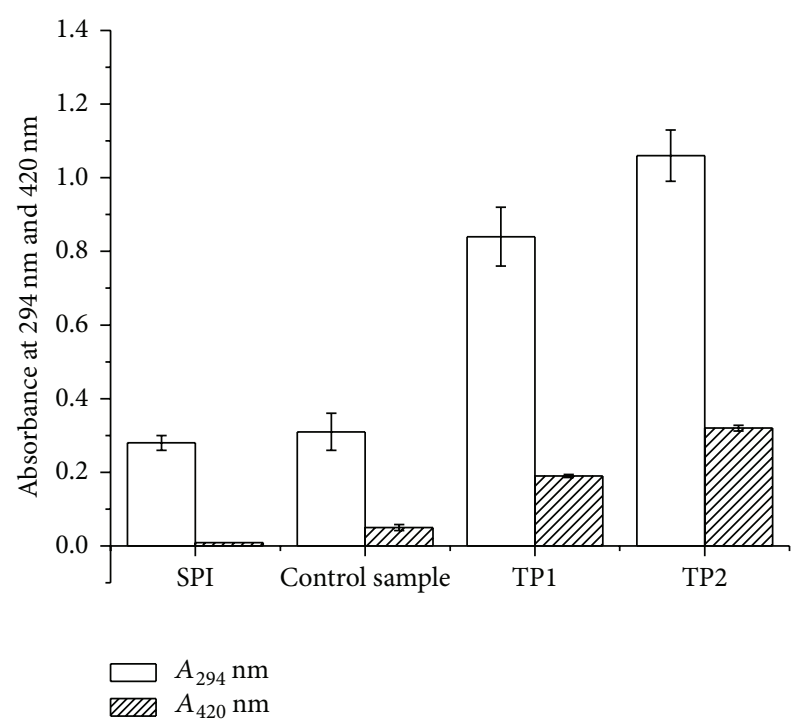

FIgURE 1: $A_{294}$ and browning intensity analysis of SPI and SPIdextran solution treated by heat and $\mathrm{TiO}_{2}$ photocatalysis (control sample, TP1 and TP2). The data with different lowercase letters in the same test are significantly $(P<0.05)$ different.

increased $A_{294}$, suggesting that the brown pigments were formed in parallel to the generated intermediate products. However, higher increase in $A_{294}$, comparing to increase in $A_{420}$, suggests high photocatalytic power could dominate the early stage of the Maillard reaction. In general, we hoped to reduce the formation of melanoidins and increase the yield of uncolored products with better functional properties.

The Maillard reaction is also associated with the development of fluorescent compounds. In the present study, formation of fluorescent compounds was observed at photocatalyzed SPI-dextran solution suggesting the formation of the resulting conjugate. Photocatalyzed samples have shown increased fluorescence with maximum at about $331 \mathrm{~nm}$ when excited at $290 \mathrm{~nm}$ originating from glycation products. Fluorescence of Maillard products was the highest in SPI-dextran solution at photocatalytic power of $1000 \mathrm{~W}$ (Figure 2) and in accordance with spectrophotometric properties of tested samples. The results suggested that photocatalysis can lead to breakage of glycosidic bonds in dextran and so more number of carbonyl groups are available for formation of SPI-dextran conjugate, similar to those induced by irradiation resulting in obvious increase in UV-absorbance and fluorescence [5].

3.2. Changes of Free Amino Groups Content. Changes in free amino group content of SPI-dextran solution after different photocatalytic power treatments are depicted in Figure 3. The free amino groups content in the SPI-dextran model system at photocatalytic power of 500 and $1000 \mathrm{~W}$ was reduced by $14.7 \%$ and $21.1 \%$, respectively, while little changes were observed in control tests. These results suggested that photocatalysis at higher power could promote the interaction between free amino groups of SPI and carbonyl group of dextran to form glycated product. From the results, it is obvious that the decrease in free amino group was in 


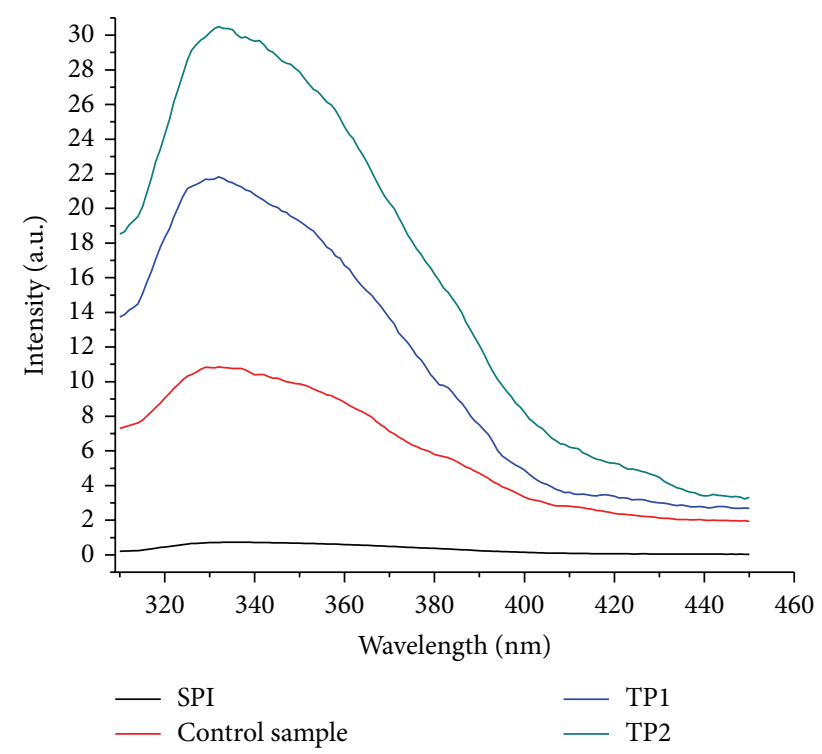

FIGURE 2: Fluorescence analysis of SPI and SPI-dextran solution treated by heat and $\mathrm{TiO}_{2}$ photocatalysis (control sample, TP1 and TP2).

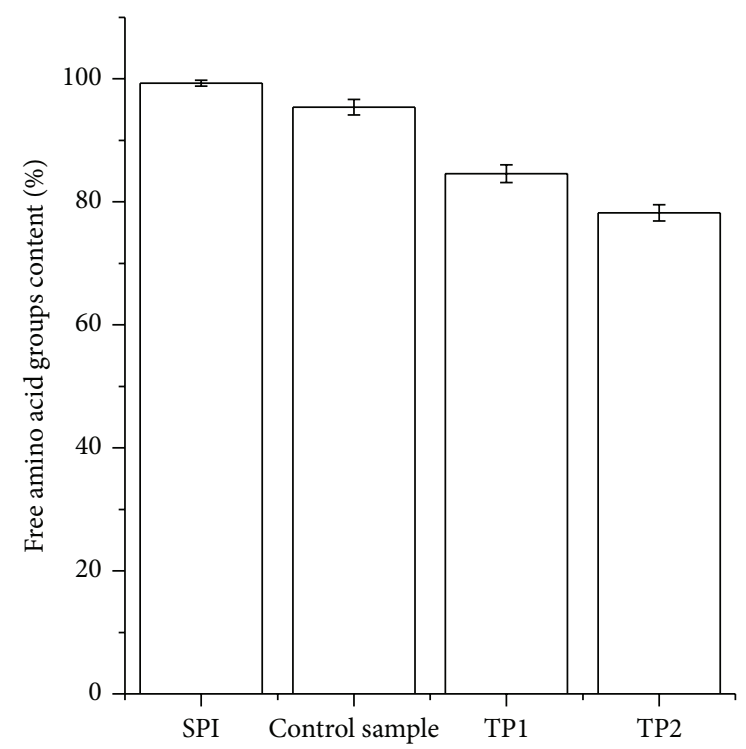

FIGURE 3: Changes in free amino groups content of SPI and SPIdextran solution treated by heat and $\mathrm{TiO}_{2}$ photocatalysis (control sample, TP1 and TP2). The data with different lowercase letters in the same test are significantly $(P<0.05)$ different.

accordance with only a small increase in browning at $420 \mathrm{~nm}$ (Figure 1), which was in accordance with the report of $\mathrm{Xu}$ et al. [19] who reported that free amino groups in $\beta$ conglycinin-dextran model system was decreased during the Maillard reaction. Therefore the effect of photocatalysis on the browning reaction and the loss of free amino groups are actually ideal for the glycation of protein and polysaccharides.

3.3. Changes in Hydroxyl Radical Scavenging Activity and Reducing Power. The hydroxyl radical scavenging abilities and reducing power were used as the standards to assess the antioxidative activity of SPI-dextran solution and the result is shown in Figure 4. Hydroxyl radical-scavenging activity ratio of SPI-dextran conjugates was significantly increased from approximately $0.81 \%$ to $11.5 \%$ and $14.2 \%$ at photocatalytic power of 500 and $1000 \mathrm{~W}$, respectively. However, no significant changes were found in the control tests within all the reactions $(P>0.05)$. The reducing power of SPIdextran conjugates (Figure 4(b)) showed similar trends with those of radical scavenging activity. The results indicate that SPI-dextran conjugates were free radical inhibitors and reducing agents as well as their concentration increased with photocatalytic power. Our findings are in agreement with an earlier report on antioxidant activity of other model systems, as a result of conjugates induced by gamma radiation in nisin model system [20].

3.4. Changes in Protein Pattern. SDS-PAGE was performed to further confirm the covalent coupling of dextran and SPI after different photocatalytic power treatment as shown in Figure 5. Initially, the dextran components in the reaction mixtures were not obtained by Coomassie blue staining; only the soy protein subunits were observed. The soy protein subunit bands in the control test are slightly lighter than the untreated sample. On the other hand, photocatalytic power exhibited a pronounced effect on crosslinking. More soy protein subunits disappeared as the photocatalytic power intensity increased. The new faint bands with much higher molecular weight on the top of the gel were observed in SPI-dextran conjugates by $\mathrm{TiO}_{2}$ photocatalysis, indicating that a large amount of new amino groups was exposed and reacted with carbonyl groups to form Maillard-based aggregates gradually because most noncovalent interactions are generally disrupted in SDS-PAGE; this was shown in the browning and free-amino analysis. These materials and the high molecular weight may be related to its reducing power and hydroxyl radical-scavenging activity. Similar SDSPAGE was found by Zhang et al., who reported that covalent conjugating compounds were produced in $\beta$-conglycinindextran model system treated by heating [21].

3.5. FT-IR Analysis. The spectroscopic analysis of polymeric molecules, including proteins, is complex due to the molecular vibrations arising from numerous atoms. FT-IR spectroscopy is a particularly useful technique for the study of protein-carbohydrate systems, as there are several readily identifiable regions of the mid-infrared spectrum where the chemical fingerprints of carbohydrates and proteins do not overlap significantly. As shown in Figure 6, a major band at $3299 \mathrm{~cm}^{-1}$ was observed in the spectra of SPI. This peak was denoted to the stretching of hydrogen-bonded $\mathrm{O}-\mathrm{H}$ groups. Meanwhile, SPI exhibited two characteristic bands at 1649 (amide I, C=O stretching) and $1535 \mathrm{~cm}^{-1}$ (amide II, N-H bending) [22]. For SPI-dextran conjugates, the regions of $1649 \mathrm{~cm}^{-1}$ and $1535 \mathrm{~cm}^{-1}$, which are referred to as $\mathrm{C}-\mathrm{O}$ and $\mathrm{C}-\mathrm{N}$ stretching from amide I and II, were modified by the Maillard reaction (Figure 6). Compared with intact SPI, the SPI-dextran conjugates at at photocatalytic power of $1000 \mathrm{~W}$ rendered the lowest intensity. It might be expected that the 


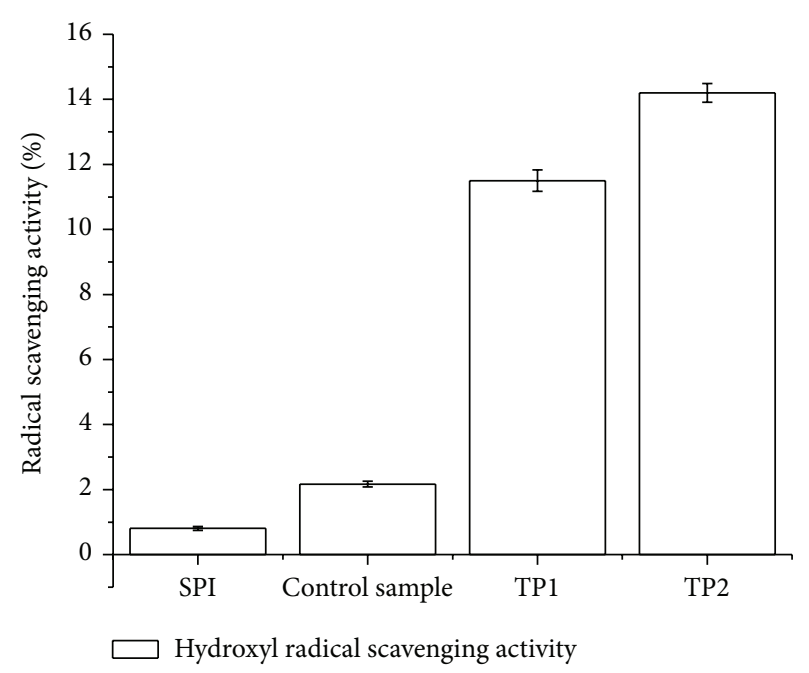

(a)

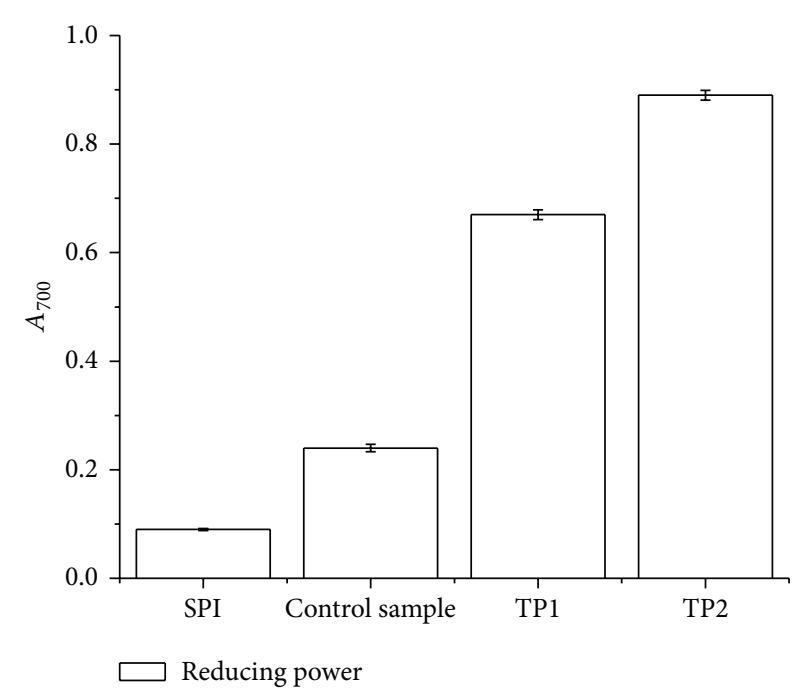

(b)

FIGURE 4: Changes in hydroxyl radical scavenging activity (a) and reducing power (b) of SPI and SPI-dextran solution treated by heat and $\mathrm{TiO}_{2}$ photocatalysis (control sample, TP1 and TP2). The data with different lowercase letters in the same test are significantly $(P<0.05)$ different.

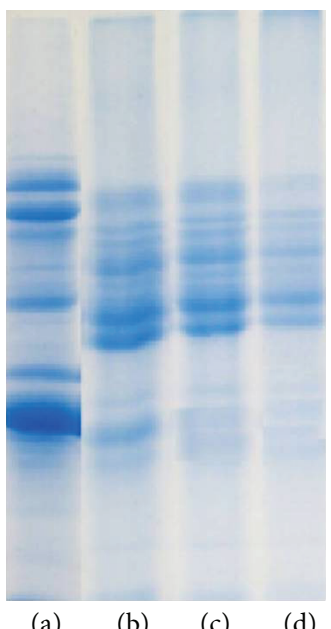

FIGURE 5: SDS-PAGE of protein patterns of SPI and SPI-dextran conjugates obtained by heat and $\mathrm{TiO}_{2}$ photocatalysis. ((a) SPI; (b) control sample; (c) TP1; (d) TP2).

$-\mathrm{OH}$ group in dextran and the amino groups in SPI are consumed in reaction mixture under $\mathrm{TiO}_{2}$ photocatalysis treatment. Su et al. [22] found a gradual decrease in the intensity of the bands at $1600-1400 \mathrm{~cm}^{-1}$ during the Maillard reaction between carboxymethyl cellulose (CMC) and soy protein isolate (SPI). For carbohydrates, a series of overlapping peaks located in the region of $1180-953 \mathrm{~cm}^{-1}$ results from vibration modes such as the stretching of $\mathrm{C}-\mathrm{C}$ and $\mathrm{C}-\mathrm{O}$ and the bending mode of $\mathrm{C}-\mathrm{H}$ bonds. These are often referred to as the "saccharide" bands and are the most intense bands in the mid-infrared spectrum. These absorptions are weak in the spectra of most proteins [23]. The absorptions in the region of

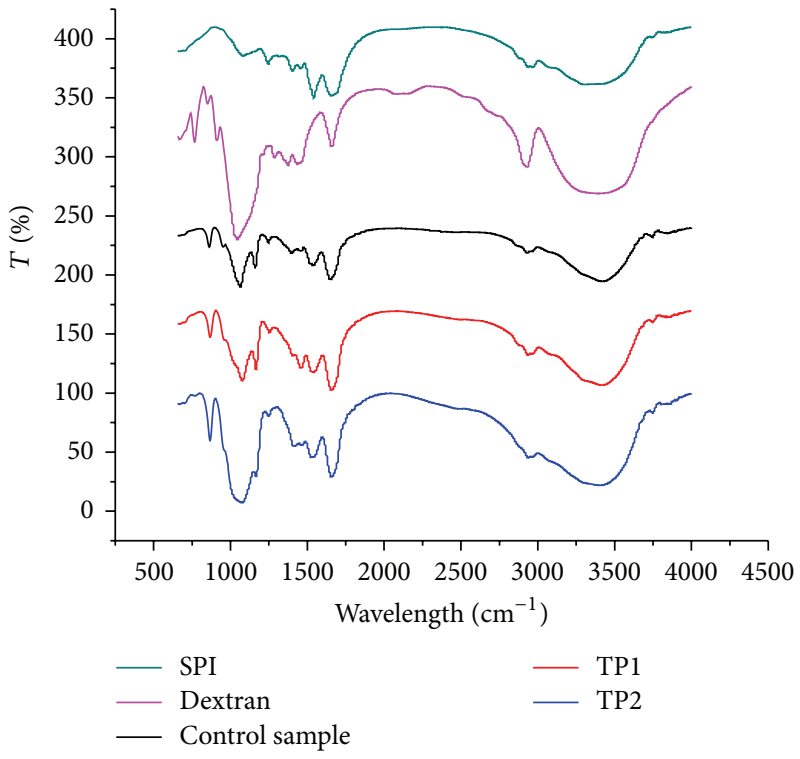

FIGURE 6: Infrared spectra of SPI, dextran, and SPI-dextran conjugates obtained by heat and $\mathrm{TiO}_{2}$ photocatalysis (control sample, TP1 and TP2).

$1180-953 \mathrm{~cm}^{-1}$ were stronger in SPI-dextran conjugate at the different photocatalytic power and the control sample than in SPI and weaker than dextran, indicating that there seemed to be a saccharide attached to the SPI. In addition, in proteins, there is an amide III band at $1300-1200 \mathrm{~cm}^{-1}$. This band is known to be very complex and mainly arises from $\mathrm{C}-\mathrm{N}$ stretching and $\mathrm{N}-\mathrm{H}$ deformation. The entire spectral features of the amide III band for the SPI-dextran solution at 500 and $1000 \mathrm{~W}$ (Figure 6) showed a decrease in intensity compared to SPI and control sample. It might be expected that 
TABLE 1: Secondary structure distribution of SPI and SPI-dextran conjugates obtained by heat and $\mathrm{TiO}_{2}$ photocatalysis (control sample, TP1 and TP2). Values with the same lowercase letters are not significantly different $(P>0.05)$.

\begin{tabular}{lcccc}
\hline & $\begin{array}{c}\alpha \text {-helix } \\
(\%)\end{array}$ & $\begin{array}{c}\beta \text {-sheet } \\
(\%)\end{array}$ & $\begin{array}{c}\beta \text {-turns } \\
(\%)\end{array}$ & $\begin{array}{c}\text { Random } \\
\text { coil }(\%)\end{array}$ \\
\hline SPI & $10.6 \pm 0.2$ & $37.9 \pm 0.4$ & $12.9 \pm 0.1$ & $38.6 \pm 0.3$ \\
Control & $10.3 \pm 0.2$ & $31.5 \pm 0.3$ & $18.3 \pm 0.2$ & $40.1 \pm 0.4$ \\
sample & & & & \\
TP1 & $5.9 \pm 0.1$ & $20.3 \pm 0.2$ & $14.5 \pm 0.4$ & $59.8 \pm 0.4$ \\
TP2 & $3.8 \pm 0.1$ & $10.4 \pm 0.2$ & $17.7 \pm 0.4$ & $68.8 \pm 0.5$ \\
\hline
\end{tabular}

the chemical changes accompanying the Maillard reaction in SPI would lead to several changes in the IR spectrum as a result of the consumption of some functional groups $\left(-\mathrm{NH}_{2}\right)$.

3.6. Secondary Structure Changes. The secondary structures of dispersions of SPI and SPI-dextran conjugates under classical heating or $\mathrm{TiO}_{2}$ photocatalysis conditions were measured, and the detailed data of $\alpha$-helix, $\beta$-sheet, $\beta$ turns, and random coil levels are shown in Table 1. Native dispersions of SPI contained approximately $10.6 \% \alpha$-helix, $39.9 \%$ of $\beta$-sheet, $10.9 \%$ of $\beta$-turns, and $38.6 \%$ of random coil. Significant changes were observed after it was treated at different photocatalytic power. The $\alpha$-helix, $\beta$-sheet, $\beta$-turns, and random coil were changed to approximately $5.9 \%, 20.3 \%$, $14.5 \%$, and $59.8 \%$ after being treated at $500 \mathrm{~W}$. With increasing photocatalytic power, $\alpha$-helix, $\beta$-sheet, and random coil changed remarkably to approximately $3.8 \%, 10.4 \%$, and $68.8 \%$ at $1000 \mathrm{~W}$, whereas $\beta$-turns had only a slight change. However, slight but not significant changes were found in the control tests. Higher photocatalytic power is more effective in changing the secondary structure of soy protein in the presence of dextran. Increasing photocatalytic power can provide a larger degree of glycation, as also evidenced by the loss of free amino groups, so that more dextran was conjugated to soy protein, resulting in an increased content of disordered structure. It proved that unordered structure was dominant in the secondary structure for the glycated SPI. These changes suggested that conjugating polysaccharides to protein by covalent bonds (as shown by SDS-PAGE) can lead to conformational changes to the secondary structure of protein-polysaccharide conjugates.

\section{Conclusion}

SPI-dextran conjugate was successfully formed by $\mathrm{TiO}_{2}$ photocatalysis treatment. In particular, higher photocatalytic power prompted glycation. Significant increases were found in the antioxidant properties of SPI by its conjugation with dextran after $\mathrm{TiO}_{2}$ photocatalysis treatment. Moreover, the measured increase in antioxidant activity coincided with an increase in the UV-vis absorption and fluorescence intensity and a decrease in free amino group content. The SDS-PAGE showed that a new high molecular mass was produced and original soy protein subunits disappeared after the conjugation induced by $\mathrm{TiO}_{2}$ photocatalysis. The spectroscopic analysis using the FT-IR technique indicated that the amide I, II, and III bands of SPI were modified by dextran after $\mathrm{TiO}_{2}$ photocatalysis treatment. Additionally, CD spectroscopy result further confirmed that glycation could change soy protein secondary structure at higher $\mathrm{TiO}_{2}$ photocatalytic power. These results suggested that $\mathrm{TiO}_{2}$ photocatalysis could potentially be applied as an effective way for forming protein and polysaccharide conjugates. Further work on conjugation between SPI and polysaccharides with $\mathrm{TiO}_{2}$ photocatalysis treatment will be conducted to elucidate the conjugating mechanism.

\section{Conflict of Interests}

The authors declare that there is no conflict of interests regarding the publication of this paper.

\section{Acknowledgments}

We are grateful for the financial support from the NonFunding programs for Science and Technology Development of Zhanjiang (no. 2013B01053), Supported by the Open Project Program of Process of Starch and Vegetable Protein Engineering Research Center of Ministry of Education (2013ERC-01), and China Spark Program (2014GA780072).

\section{References}

[1] L. X. Mu, M. M. Zhao, B. Yang, H. F. Zhao, C. Cui, and Q. Z. Zhao, "Effect of ultrasonic treatment on the graft reaction between soy protein isolate and gum acacia and on the physicochemical properties of conjugates," Journal of Agricultural and Food Chemistry, vol. 58, no. 7, pp. 4494-4499, 2010.

[2] W. Z. Sun, M. M. Zhao, C. Cui, Q. Z. Zhao, and B. Yang, "Effect of Maillard reaction products derived from the hydrolysate of mechanically deboned chicken residue on the antioxidant, textural and sensory properties of Cantonese sausages," Meat Science, vol. 86, no. 2, pp. 276-282, 2010.

[3] X. Zhang, J.-R. Qi, K.-K. Li et al., "Characterization of soy $\beta$ conglycinin-dextran conjugate prepared by Maillard reaction in crowded liquid system," Food Research International, vol. 49, no. 2, pp. 648-654, 2012.

[4] J. A. Rufián-Henares, G. Arribas-Lorenzo, and F. J. Morales, "Acrylamide content of selected Spanish foods: survey of biscuits and bread derivatives," Food Additives and Contaminants, vol. 24, no. 4, pp. 343-350, 2007.

[5] M. S. Rao, S. P. Chawla, R. Chander, and A. Sharma, "Antioxidant potential of Maillard reaction products formed by irradiation of chitosan-glucose solution," Carbohydrate Polymers, vol. 83, no. 2, pp. 714-719, 2011.

[6] Y.-G. Guan, H. Lin, Z. Han et al., "Effects of pulsed electric field treatment on a bovine serum albumin-dextran model system, a means of promoting the Maillard reaction," Food Chemistry, vol. 123, no. 2, pp. 275-280, 2010.

[7] D. Stanic-Vucinic, I. Prodic, D. Apostolovic, M. Nikolic, and T. C. Velickovic, "Structure and antioxidant activity of $\beta$-lactoglobulin-glycoconjugates obtained by high-intensity-ultrasound-induced Maillard reaction in aqueous model systems under neutral conditions," Food Chemistry, vol. 138, no. 1, pp. 590-599, 2013. 
[8] Y. Wang, L. Li, K. Yang, L. A. Samuelson, and J. Kumar, "Nanocrystalline $\mathrm{TiO}_{2}$-catalyzed solid-state polymerization of diacetylene in the visible region," Journal of the American Chemical Society, vol. 129, no. 23, pp. 7238-7239, 2007.

[9] Y. Ide, N. Nakamura, H. Hattori et al., "Sunlight-induced efficient and selective photocatalytic benzene oxidation on $\mathrm{TiO}_{2}-$ supported gold nanoparticles under $\mathrm{CO}_{2}$ atmosphere," Chemical Communications, vol. 47, no. 41, pp. 11531-11533, 2011.

[10] X. J. Lang, W. H. Ma, Y. B. Zhao, C. C. Chen, H. W. Ji, and J. C. Zhao, "Visible-light-induced selective photocatalytic aerobic oxidation of amines into imines on $\mathrm{TiO}_{2}$," ChemistryA European Journal, vol. 18, no. 9, pp. 2624-2631, 2012.

[11] V. H. Nguyen, H. Y. Chan, J. C. S. Wu, and H. Bai, "Direct gasphase photocatalytic epoxidation of propylene with molecular oxygen by photocatalysts," Chemical Engineering Journal, vol. 179, no. 1, pp. 285-294, 2012.

[12] R. Chong, J. Li, X. Zhou et al., "Selective photocatalytic conversion of glycerol to hydroxyacetaldehyde in aqueous solution on facet tuned $\mathrm{TiO}_{2}$-based catalysts," Chemical Communications, vol. 50, no. 2, pp. 165-167, 2014.

[13] X. Zhou, F. Peng, H. Wang, H. Yu, and Y. Fang, "Carbon nitride polymer sensitized $\mathrm{TiO}_{2}$ nanotube arrays with enhanced visible light photoelectrochemical and photocatalytic performance," Chemical Communications, vol. 47, no. 37, pp. 10323-10325, 2011.

[14] R. Caillard, G. E. Remondetto, and M. Subirade, "Physicochemical properties and microstructure of soy protein hydrogels coinduced by Maillard type cross-linking and salts," Food Research International, vol. 42, no. 1, pp. 98-106, 2009.

[15] L. You, M. Zhao, J. M. Regenstein, and J. Ren, "Changes in the antioxidant activity of loach (Misgurnus anguillicaudatus) protein hydrolysates during a simulated gastrointestinal digestion," Food Chemistry, vol. 120, no. 3, pp. 810-816, 2010.

[16] L. Zheng, G. Su, J. Ren, L. Gu, L. You, and M. Zhao, "Isolation and characterization of an oxygen radical absorbance activity peptide from defatted peanut meal hydrolysate and its antioxidant properties," Journal of Agricultural and Food Chemistry, vol. 60, no. 21, pp. 5431-5437, 2012.

[17] U. K. Laemmli, "Cleavage of structural proteins during the assembly of the head of bacteriophage T4," Nature, vol. 227, no. 5259, pp. 680-685, 1970.

[18] Z.-M. Gao, L.-P. Zhu, X.-Q. Yang et al., "Soy lipophilic protein nanoparticles as a novel delivery vehicle for conjugated linoleic acid," Food and Function, vol. 5, no. 6, pp. 1286-1293, 2014.

[19] C. H. Xu, S. J. Yu, X. Q. Yang, J. R. Q. Lin, and Z. G. Zhao, "Emulsifying properties and structural characteristics of $\beta$ conglycinin and dextran conjugates synthesised in a pressurised liquid system," International Journal of Food Science and Technology, vol. 45, no. 5, pp. 995-1001, 2010.

[20] S. R. Muppalla, R. Sonavale, S. P. Chawla, and A. Sharma, "Functional properties of nisin-carbohydrate conjugates formed by radiation induced Maillard reaction," Radiation Physics and Chemistry, vol. 81, no. 12, pp. 1917-1922, 2012.

[21] J.-B. Zhang, N.-N. Wu, X.-Q. Yang, X.-T. He, and L.-J. Wang, "Improvement of emulsifying properties of Maillard reaction products from $\beta$-conglycinin and dextran using controlled enzymatic hydrolysis," Food Hydrocolloids, vol. 28, no. 2, pp. 301-312, 2012.

[22] J.-F. Su, Z. Huang, X.-Y. Yuan, X.-Y. Wang, and M. Li, "Structure and properties of carboxymethyl cellulose/soy protein isolate blend edible films crosslinked by Maillard reactions," Carbohydrate Polymers, vol. 79, no. 1, pp. 145-153, 2010.
[23] F. L. Gu, J. M. Kim, S. Abbas, X. M. Zhang, S. Q. Xia, and Z. $\mathrm{X}$. Chen, "Structure and antioxidant activity of high molecular weight Maillard reaction products from casein-glucose," Food Chemistry, vol. 120, no. 2, pp. 505-511, 2010. 

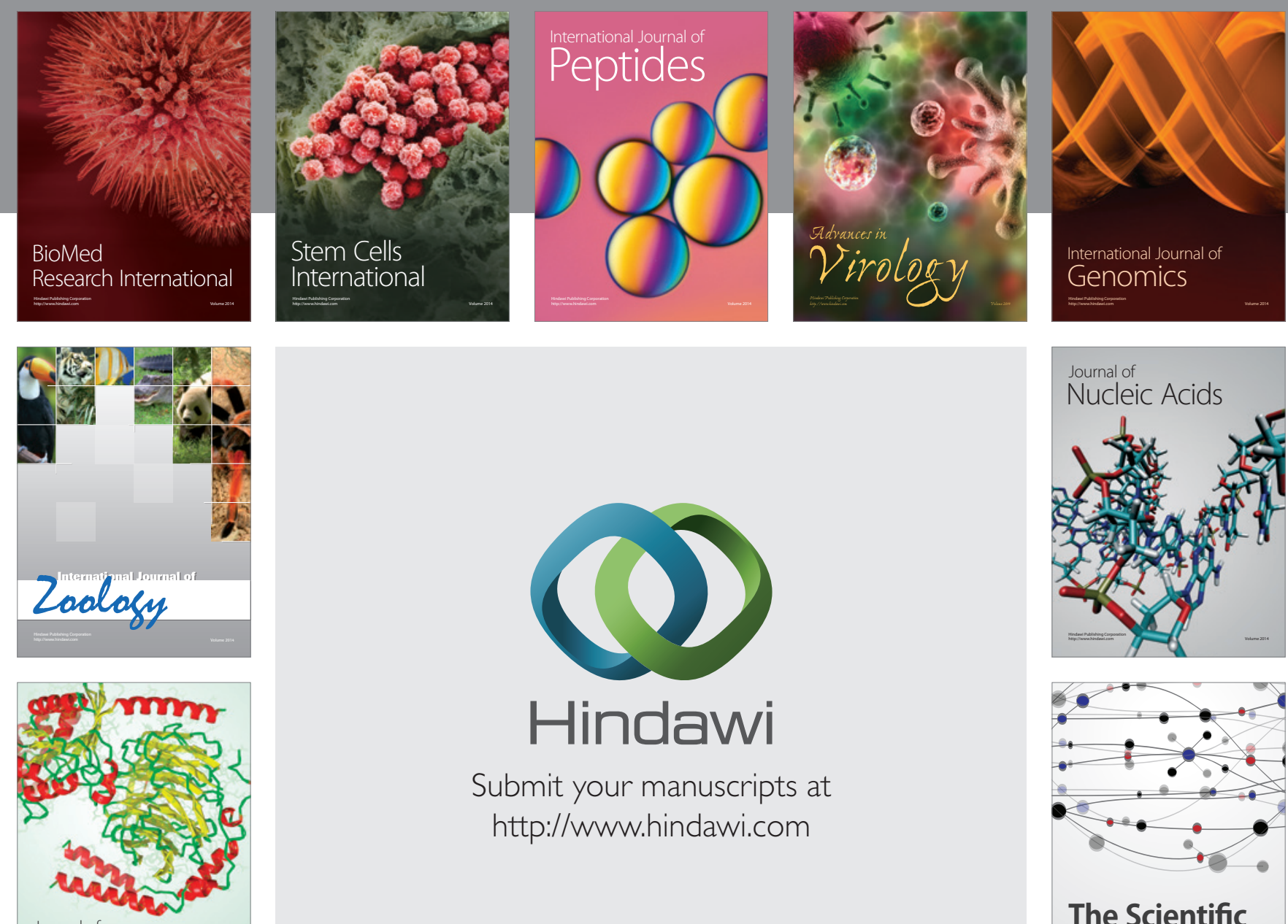

Submit your manuscripts at

http://www.hindawi.com

Journal of
Signal Transduction
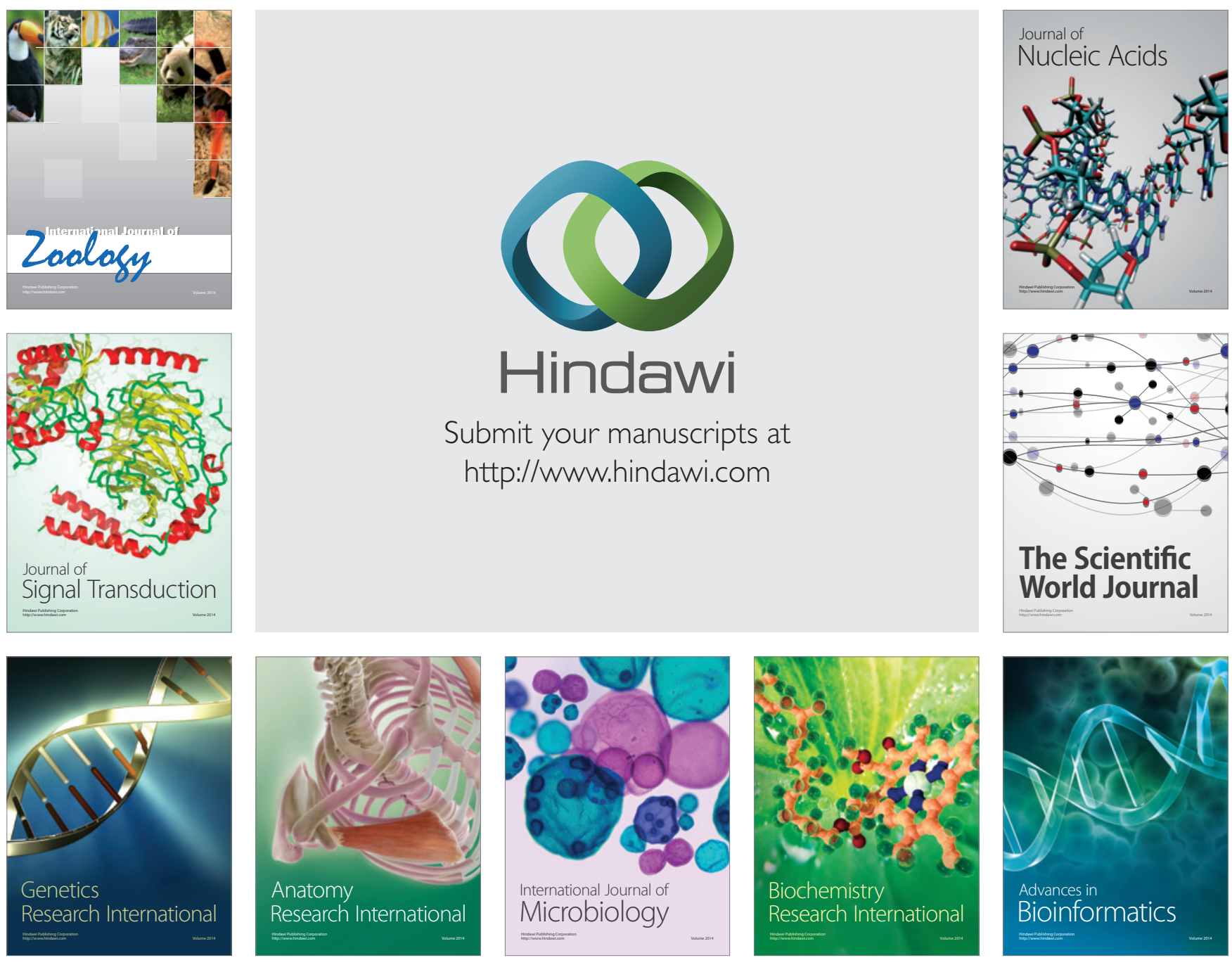

The Scientific World Journal
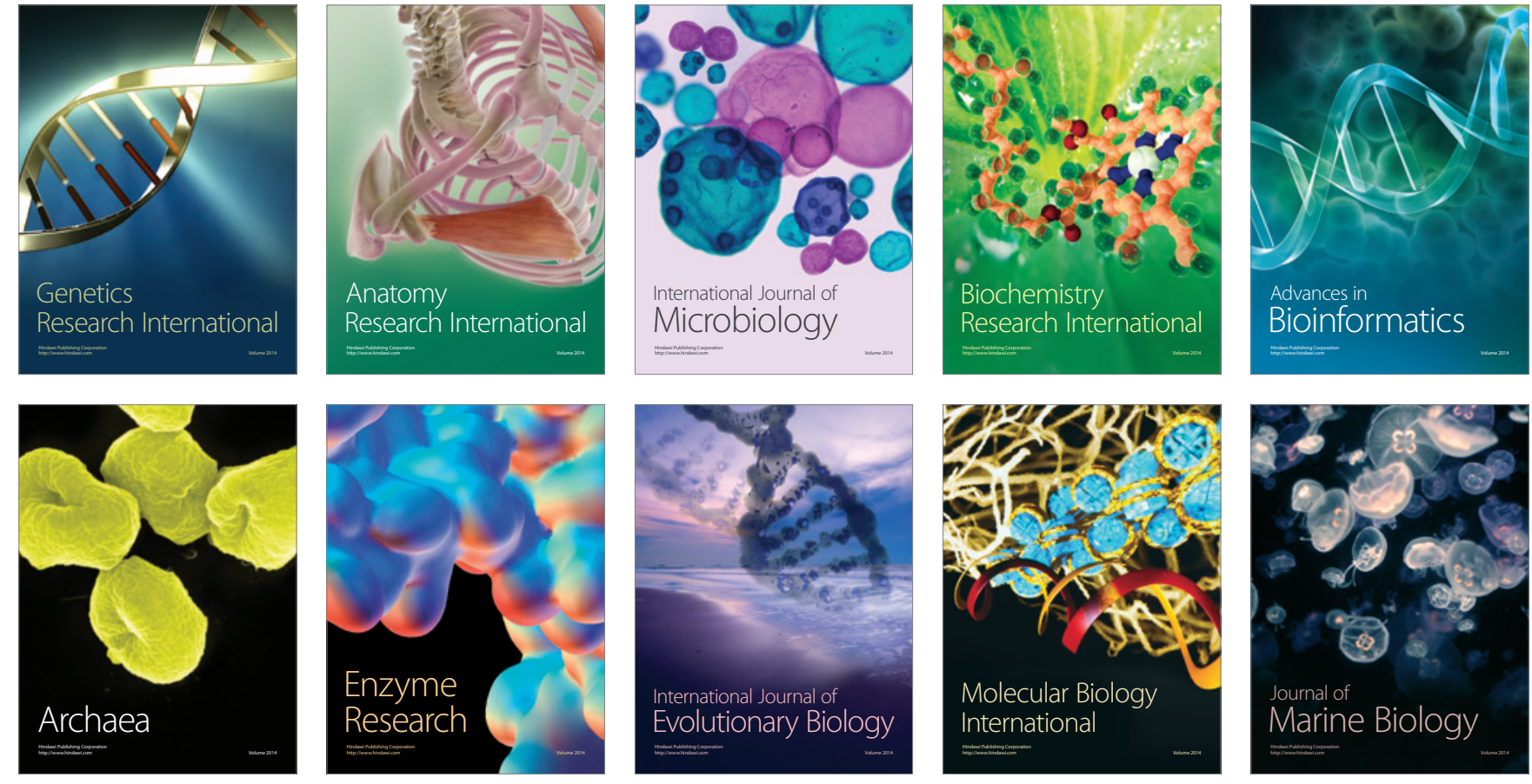